\title{
Column studies of copper(II) and nickel(II) ions sorption on palm pressed fibres
}

\begin{abstract}
The efficiency of palm pressed fibres (PPF) in removing copper(II) and nickel(II) ions from solution was investigated in column experiments. Homogeneous column studies show that metal sorption increased with lower flow rate, higher bed-depth and lower metal ion concentration. Bed-depth service time (BDST) studies show that the results agree with the BDST model proposed by Hutchins [1]. The mixed media studies using sand-soil PPF combination demonstrated that PPF can be an efficient sorbent in the prevention of leaching of metal ions in landfill.
\end{abstract}

Keyword: BDST equation; Homogenoeous column; Mixed bed; Sorption 